\title{
Cancer Communications: From Hyoid Bones to Nanochips
}

\author{
Arthur M. Michalek
}

Published online: 23 March 2014

(C) Springer Science+Business Media New York 2014

Hopefully, as you read this issue of the Journal you will be surrounded by signs of spring. As I began to write this editorial, the winds of winter howled outside my window. To some, like Coleridge [1], winter is an idyllic retreat as sweet as summer. To others, it is a tangle of canceled flights, backs made sore from shoveling, and fits of cabin fever. It also presents an opportunity to find time to tackle the mountain of books growing alongside a favorite easy chair. My typical reading list is rather atypical, and this season's readings ranged from archeology to zoology with a few novels thrown in for good measure. One piece that struck a chord with me was an item in archeology which recounted the discovery of a nearly intact, 60,000 year-old human skeleton [2]. Anatomical examination revealed the presence of a hyoid bone which investigators speculate would have allowed our ancestors the ability to engage in complex speech. Even more remarkable is the discovery of the hyoid bone, not yet studied, of a 500,000 year-old Homo heidelbergensis. If anatomical examination is confirmatory, this suggests that our ancestors were able to engage in oral conversations nearly 500,000 years ago or, for you numerists, 5 lakhs or half a Mak. That really got me thinking...about communication. There can be little debate that significant changes have occurred to mankind and our social environment since $H$. heidelbergensis roamed the earth. And yet, while we have eschewed the cave for more comfortable domiciles, gone from eating raw rhino to a well-done burger, replaced the stone tipped spear with other more heinous and efficient weaponry, and worry more about "the" web

A. M. Michalek ( $₫)$

Doctoral Programs Health Policy \& Health Education Health

Administration, D'Youville College, Buffalo, NY, USA

e-mail: jceditor1@gmail.com

A. M. Michalek

Roswell Park Cancer Institute Graduate Division, University at Buffalo, Roswell Park, USA rather than a spider web, we continue to struggle with communication. Certainl,y our collective vocabulary has grown. We have amassed libraries full of written words that educate, entertain, and inspire us. Yet, in some ways, we have not really changed. Our libraries are a repository of our literary evolution containing works ranging from Beowulf to works cited in the latest best seller list, works whose meaning need be rediscovered by each new generation. Yet while mankind's hyoid has remained relatively unchanged, individual members of the species must relearn how to communicate. The first part of the how - the actual mechanics and base meanings of speech take the average human until age 5 or 6 to begin to master. They begin with one word sentences, then two, three, etc. Soon, almost by magic, they begin communicating concepts evolving from a crying child who is hungry to one who states "want chee-chees" (my own children's early requests for Cheerios).

As we evolve both personally and professionally, our need to develop more complex communications increases. This is especially evident in the area of healthcare. When I began in this profession, more years ago than I care to profess, the pamphlet was considered an avant-garde means of patient communication. We debated the message, reading level, layout, colors, and pictures. The belief was that if the patient reads our message, then they would change their behavior. Unfortunately, this was not the case, and our approach has since changed dramatically. The literature is replete with articles proposing, evaluating, and revising approaches to patient, public, and professional communication. There are entire journals devoted to the topic such as Communication \& Health Outcomes, Communication and Medicine, Health Communications, and many more. The number of articles published in this area has grown exponentially. A quick search via Scopus revealed that in 1994, there were approximately 100 articles published in the realm of communication and cancer. That number grew to nearly 300 in 2003 and 
approached nearly 700 in 2013 . The topics contained therein have also become more complex. Communication is central to all aspects of cancer care regardless of whether the topic be prevention, screening, treatment, or rehabilitation/survival. Arguably, every article in the Journal of Cancer Education involves some facets of communication. Some focus on patient communications such as breaking bad news, some on community education such as improving cancer prevention or behavior modification, and still others on enhancing student or peer competencies. The variations are far-ranging. We as readers of the journal strive to improve upon the delivery of information so that it is understood, retained, and acted upon by a variety of constituencies.

Our collective goal is to improve John Q. Public's health literacy IQ and associated quality of life. However, we do not work in a vacuum, and our success at the minimum will require society's success in improving high school graduation rates and reducing associated poverty. In some areas, high school graduation rates are below $50 \%$. According to the census, nearly 1 of every 7 Americans lives in poverty. Poverty rates are closely aligned with race/ethnicity which also correlates with health disparities. Census figures reveal that $12.3 \%$ of non-Hispanic whites were living in poverty in 2009, while a quarter of Hispanics (25.3\%) and blacks $(25.8 \%)$ were living in poverty [3]. Without such social gains, we will not make a dent in the public's understanding of the need to be (or not to be) screened, the importance of therapeutic trials, the value of genetic tests, or any other of the complex messages invoked by today's and tomorrow's health challenges. Sad truths are that we are not solely in control of our own professional destiny.

As educators, we have continuously reinvented the tools and techniques employed to produce gains in knowledge and/ or behavioral change. We must remain ever vigilant for new opportunities to affect personal change whether that is through system or individual change. In my winter's quest to begin to understand communications, I read Health Communication by Thomas [4] and Selling the Invisible by Beckwith [5]. Thomas presents a highly readable overview of theories and practice of health communication. Thomas points out that in the future, consumers will enjoy even greater access to information. Currently, available services such as WebMD and Ask the Doctor will continue in popularity and likely adapt to changing consumer care-seeking modalities. Twenty years ago, these services were not even thought of. What will the next 20 years make possible? Will we have nanochip implants with direct cerebral connection instantaneously relaying terabytes of information from some omniscient source? How will we as health educators identify and take advantage of these opportunities? Regardless of the mode of conveying our information, we must work on the message. This will require us to expand our repertoire to include effective marketing. As Beckwith recommends, we need to give the consumer one good reason to change, repeat it again and again, and use stories not adjectives. I can only hope that our successes and failures will be recounted in the Journal of Cancer Education and that in the years to come, the journal's collection may be viewed as a literary fossil record of how we evolved to effect change. I have no answers, just questions and hope.

While we contemplate improvements in cancer communications, may we also take the time to enjoy hearing the world through a child's words as they begin their own adventures in communication. As my 6-month-old grandson Wally would say "Ah-boo." I have no idea what it means, but he smiles when he says it!

Be well.

\section{References}

1. Frost at Midnight, Samuel Taylor Coleridge (1798)

2. Neanderthal bone could push back evolution of complex speech. Archaeology http://www.archaeology.org/news/1687-hyoid-bonetongue-speech-neanderthals

3. Census Ref: United States Census Bureau. The 2012 Statistical Abstract. http://www.census.gov/compendia/statab/cats/income expenditures_poverty_wealth/poverty.html

4. Thomas Richard K (2006) Health communication. Springer, New York

5. Beckwith H (1997) Selling the invisible. Warner Books, New York 